Meta

Journal des traducteurs

Translators' Journal

\title{
Text Classification and Text Analysis in Advances Translation Teaching
}

\section{Peter G. Emery}

Volume 36, numéro 4, décembre 1991

URI : https://id.erudit.org/iderudit/002707ar

DOI : https://doi.org/10.7202/002707ar

Aller au sommaire du numéro

Éditeur(s)

Les Presses de l'Université de Montréal

ISSN

0026-0452 (imprimé)

1492-1421 (numérique)

Découvrir la revue

Citer cet article

Emery, P. G. (1991). Text Classification and Text Analysis in Advances

Translation Teaching. Meta, 36(4), 567-577. https://doi.org/10.7202/002707ar
Résumé de l'article

On étudie d'abord les différentes bases théoriques sur lesquelles se fonde la classification des textes tout en préconisant comme critère prépondérant le domaine ou « contexte social ». On traite des méthodes d'analyse de textes en tenant compte de certaines théories linguistiques. Enfin, on souligne l'importance de l'analyse textuelle dans la pédagogie de la traduction. Les exemples illuslrafifs sont tirés de traductions arabe/anglais. 


\title{
TEXT CLASSIFICATION AND TEXT ANALYSIS IN ADVANCED TRANSLATION TEACHING
}

PETER G. EMERY

Sultan Qaboos University, Sultanate of Oman

\begin{abstract}
Résumé
On étudie d'abord les différentes bases théoriques sur lesquelles se fonde la classification des textes tout en préconisant comme critère prépondérant le domaine ou "contexte social». On traite des méthodes d'analyse de textes en tenant compte de certaines théories linguistiques. Enfin, on souligne l'importance de l'analyse textuelle dans la pédagogie de la traduction. Les exemples illustratifs sont tirés de traductions arabelanglais.
\end{abstract}

Pedagogically, it is a commonplace that translation courses expose students to a variety of samples of natural language (SL) for transfer into another natural language (TL) and that these samples constitute "the verbal record of a communicative act" (Brown and Yule 1983: 6) or texts. However what has long been the subject of debate is the theoretical framework upon which classification of such texts should be based and the methods to be utilized in dealing with texts in the translation-teaching context. This paper addresses these two issues: the first part considers various theoretical bases for text classification and elects the criterion of domain or "social context" as the determining factor. The second part deals with methods of text analysis and proposes an integrated approach encompassing insights from a number of linguistic theories. Finally, consideration is given to the role of text analysis in translation pedagogy and ways in which trainee translators' sensitivities to this aspect can be heightened. The discussion in this paper is intended to be "language-pair independent" but illustrations of specific points are drawn from Arabic and English translation where appropriate.

\section{CLASSIFICATION OF TEXTS}

Currently the most "authoritative" approach to classification is derived from text linguistics and generally takes the shape of a taxonomy of text-types, text-forms and textsamples (or text-form variants). Werlich (1976) characterized text-types as "idealized norms of distinctive text structuring" and proposed a five-fold typology: description, narration, exposition, argumentation and instruction. This scheme is adopted by Zydatiss (1983) but Hatim (1984) conflates the first three types into a single category (expository). Text-forms and text-form variants are conventional manifestations of a text-type, the latter giving prominence to context-indicators such as field, tenor and mode (ibid.). Yet, for the purposes of text classification there are two interrelated problems associated with this kind of typology. First, the notion of text-type is of such wide applicability that it can subsume a bewildering range of text-form variants (e.g. under "instruction" Zydatiss mentions Acts of Parliament, technical instructions, recipes, political speeches, sermons, advertisements and leading articles). Secondly, a particular text normally consists of different text-types e.g. an instruction manual may be expository and descriptive as well 
as instructional. The upshot is that the notion of text-type, while perfectly clear as a theoretical construct and analytical tool is of little practical benefit in classifying actual texts for pedagogical purposes - a conclusion implicit in Werlich's earlier definition because of the difficulty of linking particular text-samples with particular text-types in a plausible and systematic way. A second approach, based on text function, runs into similar difficulties - the criterion is at once too inclusive and too "includable" to constitute a cogent framework for text classification. One problem is that the notion of text function is not yet "delicate" enough; conversely, several functions may be discerned in a text and these may even be at variance with its macro-function. On this point Schmidt (1978: 55) comments:

...the problem of possible and/or expectable hierarchies of communicative text functions must be solved; because one text can fulfill different communicative functions in one and the same situation (e.g. persuade and warn)... or parts of a text may fulfill different partial functions (which may conflict with the function of the text as a whole).

Hence, for example, Zydatiss identifies, in addition to predominantly directive and referential functions, a phatic function in his technical instruction text, observing that it is "text-pragmatically not a monolithic whole. It does not only contain 'material' representing the 'directive' function of language. It also has language in it which serves other functions" (id:: 214). Following Halliday, House (1981) classifies her texts for analysis into two "macro-functions": ideational and interpersonal, subdividing them into notional categories - technical/non-technical and fictional/non-fictional. Aside from the possible difficulty of combining functional and notional categories, there is a more serious objection to categorising texts on the basis of this macro-distinction, which lies at the heart of language. It is arguable that all discourse fulfills both an ideational and an interpersonal function since (to put it simply) the speaker (addresser) must have something to say (message) and (ultimately) someone to say it to (addressee). Indeed the theoretical premise of House's classification is at odds with her earlier definition of translation as "the replacement of a text in the source language by a semantically and pragmatically equivalent text in the target language" (id.: 29-30). If a translation is "an act of communication" a text is no less "a unit of language in use." A further difficulty with House's scheme is that poetic-aesthetic texts find no place in the classification since they are more "form-oriented" than interpersonal and when rendered into TL become "no longer a translation but a kind of creative transposition" (id.: 69). Clearly, a scheme which excludes such texts is likely to be of limited value in underpinning any broadly-based translation course.

Tackling the problem from the point of view of speech act theory brings some solutions but adds other difficulties: Van den Broeck (1986: 38) mentions Van Dijk's concept of a macro-speech act as one of the bases for distinguishing different types of discourse and contends that "for every type of illocutionary force there is a corresponding type of discourse" e.g. assertive discourse "the global function of which consists in describing or representing states of affairs in a real or possible world" and reflexive, ritual, or poetic discourse "in which the utterance itself is focussed on for its own sake." Van den Broeck recognizes "that such a rough classification oversimplifies things as they really are in that it is practically impossible not to take into account various forms of cross-classification" and that "within one and the same piece of discourse speech acts of different types may occur at the same time." Under such a classification, literary and poetic texts are well catered for but what are we to make of the assertive category which could encompass inter alia fictitious and non-fictitious descriptions, news reports, advertisements, and technical reports? Such a broad category is counter-intuitive, at least 
in the absence of significant theoretical advances in text-linguistics. Schmidt (ibid.) proposes two solutions to the problems of text-typology:

Either one starts with pre-theoretically characterized types of text (as objects under observation) and tries to produce a formal reconstruction of the heuristically assumed types by means of a consistent text theory; or one constructs an efficient text theory which allows the production of text types as theoretical constructs, which may then be empirically tested.

The difficulties associated with the latter (deductive) course - at least in the present "state of the art" - have already been referred to, so what of the former (inductive) approach? The analysis of texts as "objects under observation" has a long history in modern linguistics, rooted in Firth's "context situation" and developing via Jakobson's "language in operation" into Labov's conception of "discourse analysis" as an investigation of the rules of language in action. A fundamental principle in such an approach to language in its social context is the primacy of the (linguistic and) extralinguistic context: as Halliday (1978: 28) puts it -

Essentially... language comes to life only when functioning in some environment. We do not experience language in isolation - if we did we would not recognize it as language - but always in relation to a scenario, some background of persons and actions and events from which the things which are said to derive their meaning... any account of language which fails to build in the situation as an essential ingredient is likely to be artificial and unrewarding.

A pioneering attempt to identify particular texts with particular "situations" was that of Crystal and Davy (1969) who explored the relation between linguistic features and situational variables. Although they distinguished subject-matter from the extra-linguistic context (thus removing one of the objections to register analysis viz. the circularity or self-defining nature of the earlier concept of "register") their method of stylistic analysis was criticized by Widdowson (1979: 90-94) as being too "atomistic" and failing to deal adequately with "text" in the sense of "sentences in combination". A major situational dimension in Crystal and Davy's analysis is "province" which is constituted of "those variables in an extra-linguistic context which are defined with reference to the kind of occupational or professional activity being engaged in" (1969: 71). Although Crystal and Davy deny that this dimension is theoretically prior to other dimensions, yet, because of the pre-theoretical standing of this "established stylistic concept" they concede that, in fact, "it is usually easier to begin by looking for province features in any analysis" (id.: 73). Mason renames the dimension "domain" and broadens it to encompass "social context, distinguishing a number of "domains": scientific/technical, administrative, political, etc. Since "social contexts" or "environments" are analytically anterior (if not logically prior) to other situational dimensions such as "status" or "modality," it makes sense to set up a classification of texts on the basis of the pre-theoretical notions which are already available. There remain two problems: first, where to draw the upper bound of generality of the notional categories and where to draw the lower limit of specificity. Based on Mason's list we could identify the following domains:

scientific/technical
administrative
political
religious

literary journalistic legal sales

These in turn could be subclassified into "sub-domains" or "forms 1 ": scientific/technical: technical report, research paper, school text-book 
administrative: permits, regulations, notices, tenders

political: speech, pamphlet, treatise, tract

religious: religious text, sermon, hadith

literary: novel, essay, short story, poem, drama

journalistic: news report, editorial, feature article

legal: treaties, contracts, court-judgements, procès-verbaux

sales: adverts, business letters, tourist information booklets, instruction booklets

Naturally, overlap also occurs in the above categorisation - e.g. a newspaper editorial may be assigned to the "political" domain and an instruction booklet may fall under "scientific/technical" according to the complexity of the material, but untidiness is unavoidable in all natural linguistic systems. On the other hand such a classification avoids the difficulties of text-type/function or speech act models by operating with pretheoretical categories and subcategories which are already familiar and do not, on the whole, need to be empirically tested to establish their theoretical legitimacy, thus leaving the way clear for cross-linguistic research into the ways in which such categories are "realized" in language-pair bound descriptions. The second problem relates to the status of the concept of domain/province as a basis for setting up a typology of texts. Although "province" is only one of a number of situational dimensions in Crystal and Davy's scheme, yet it has procedural priority over the other dimensions of "modality," "status" and "singularity" and it would be impractical to utilize any of these as a classification criterion. Also, province/domain is a pre-theoretically established category rather than a theoretical construct as are the other situational dimensions and consequently does not need pre-testing but rather refinement. A more serious objection may be put forward: a "situation-based" approach to the classification of texts may not give enough weight to their pragmatic dimension especially since translation is "a speech event, a communicative act which is carried out by somebody in a specific context and for a specific or special purpose" (Lindquist 1988: 46). However, it is only because of the theoretical limitations of functional/speech act typological models that the domain-based classification is proposed. A further criticism of Crystal and Davy's method of stylistic analysis was the lack of attention paid to the textual dimension:

I think that the essential shortcoming of register/general stylistic analysis... is that it does not provide teachers with any directions as to how they might move from the sentence to the text. (Widdowson 1979: 94)

Clearly such objections are valid - but only in relation to text analysis rather than text classification: the latter must await fully-developed text-linguistic and speech act theories. However in the former case, the insights of such theories must be utilized to the full in combination with "situation-based" stylistic analysis.

What has been proposed in this section is an inductive approach to the classification of texts for the purpose of translation pedagogy which avoids the pitfalls of the "subjectbased" type of Hallidayean register analysis and, at the same time, the difficulties involved in applying recent theoretical advances in linguistics to the problem in a deductive way. Even so, selection of a particular linguistic theory by no means precludes consideration of other theories and it is in the actual teaching context that the disciplines of text-linguistics, speech act theory and discourse analysis combine with stylistic analysis to play a vital role. 


\section{TEXT ANALYSIS}

In the "linguistic" period of translation theory it is probably true to say that more emphasis has been put on the transfer and restructuring phases of the translation process than the analytical phase. Although in their three-phase model Nida and Taber characterized "transfer" as "the crucial and focal point of the translation process (1969: 99), it was the restructured form that Catford focussed on in his concept of "textual equivalence" and this was also the main thrust of traditional contrastingly-oriented theories of translation which "concentrated on translation problems stemming from differences in the linguistic systems of the source and target languages" (House 1986: 7). It is with the application of text-linguistics to translation that the importance of the analysis has been reasserted [see for example Zydatiss (1983: 220), Wilss (1983: 147) and House (ibid.) $)^{2}$. The translator must be "able to decode the text properly" and this involves a full appreciation of the text in all its dimensions:

Any text analysis, if it wants to achieve untrivial results, must envisage the total constitution of a text, in its thematic, functional and in its stylistic dimension or, in semiotic terminology, any text analysis must deal with the syntactic, the semantic and the pragmatic text level, with syntax and lexis functioning as instruments for the establishing of the text-pragmatic level. (Wilss ibid.)

Text analysis therefore is an integral part of the translation operation, "an appropriate training for translators" (Newmark 1988: 17) and an exercise which "may well serve to render the trainee translator more sensitive to the multi-faceted nature of translation equivalence" (Mason 1982: 27). Further, text analysis, unlike text classification should not be based upon a single (linguistic) criterion but upon a multiplicity of criteria: it should be as comprehensive and multidimensional as possible. Some writers have endeavoured to apply a single set of criteria for classification and evaluation/analysis of texts: for House (1977) texts are classified functionally and an adequate translation text is functionally equivalent to its source text, while Hatim (id.: 49) proposes text linguistics as a basis for "selection, grading and presentation of materials for the advanced translatortrainee." Such proposals, while admirable in their consistency are unnecessarily constraining: the translator-trainee needs to be made aware of as comprehensive a range of approaches to linguistic analysis as possible. In the following sections I will consider several models of text analysis and propose an integrated approach. I will then describe the methodology and role of text analysis in an advanced translation-teaching context.

\section{MODELS OF TEXT ANALYSIS}

Approaches to text analysis in translation all share a common goal: the elucidation of the linguistic features of the source text for the purpose of reproducing or evaluating a (maximally) equivalent target text. Mason (1982) proposes a three-dimension model: the text should be analyzed according to domain, tone (by which he means "style" or "formality") and function. The latter category is problematic since it constitutes a "mixed-bag" of text types and functions: e.g. "descriptive," "narrative," "inflammatory," "jocular," etc. After sifting out text types from Mason's global category, it is possible to distinguish two notions here: the function of a text (text-centred) and the intention of the writer/speaker (producer-centred). The former notion is subclassified by Newmark (1988) (following Buhler and Jakobson) into three main functions (expressive, informative, and vocative) and three subsidiary functions (aesthetic, phatic and metalingual). The latter notion is equivalent to Beaugrande and Dressler's textual standard of "intentionality," a category which encompasses a wide variety of purposes such as "warning," "persuading" (as well 
as "inflammatory," "jocular" listed above). While there can be overlap between the three categories distinguished (e.g. an "instruction" text type by which the text-producer wishes to instruct), this is not necessarily the case (i.e. an "informative" text may be predominantly "expository" and the intention of the text-producer may be to "warn"). Newmark (1988) advocates close reading of a text in order to determine its intention: for him the intention of the text and that of the author are co-extensive but, as has been shown, this is not inevitably so. On the other hand, as Newmark observes, the translator's purpose as producer of the target text may well be at variance with the author's as producer of the source text (see on this Lindquist 1988). Following Nida, Newmark distinguishes four text styles: narrative, description, discussion, and dialogue (the first two being text-types and the second two [loosely] being "genres") and after emphasizing the consideration of the "readership" in the production of the target-text, sets out three stylistic scales to be applied in text analysis: formality, generality/difficulty, and emotional tone. Of these three, while the former and the latter are vital and useful respectively, the scale of generality/difficulty seems highly subjective and difficult to apply (except perhaps in scientific texts). Newmark's last two categories - "attitude," and "setting" — overlap with "quality of the writing" and "readership" respectively. A general objection to Newmark's approach is that it is at once a method of tackling a translation text (reading the text, the last reading) and a set of criteria for text evaluation but, pedagogically, it is often desirable to keep theory and practice distinct. For House (1981) text analysis is carried out in order to state precisely the equivalence between source text and translation text with a view to evaluating functional correspondence. Her analysis model is adapted from Crystal and Davy's stylistic analysis, situational dimensions being divided into those of language-user and those of language use. Like Crystal and Davy, House differentiates syntactic and lexical means which "realize" the situational dimensions but she adds a category of "textual" means, perhaps mindful of Widdowson's criticism of their "atomistic" approach. The analysis concludes with a statement which summarizes the text's function and the role of the situational dimensions in achieving this function.

Zydatiss (1983) first distinguishes between objective and subjective presentation, a distinction which runs through all five text types. In fact the distinction corresponds to Halliday's ideational (content-oriented)/interpersonal (role-oriented) "split," but as we suggested earlier it is perhaps more plausible to view this dichotomy as potentially "realisable" in all texts rather than hiving off text-forms into "subjective" and "objective" categories as Zydatiss does. Stylistic analysis models recognize this in their generallyapplicable situational dimensions of status, social role relationship, and social attitude. In his text analysis Zydatiss gives prominence to text pragmatics and text structure (including interlingual structural contrasts) and concludes with a third category of lexical cohesion and topical coherence. Situational information (such as SL/TL addressee characterisation and formality/informality) is introduced incidentally within these three major analytical dimensions. 
Figure 1

\title{
AN INTEGRATED APPROACH
}

\author{
Text Analysis
}

Text title:

Domain:

Form:

\section{MACRODIMENSIONS}

1. Situational Dimensions

* Variety of language

* Medium (simple/complex)

* Formality addresser/addressee role relation/profiles style: frozen-intimate

* Domain/form-specific features

2. Text pragmatics

* Function(s) of text/text-type(s)/purpose(s) of text-producer

* Speech acts/illocutionary force

* Text structure (coherence/cohesion)

* Text tone

3. Text semiotics

* Culture-located signs

* Intertextuality

\section{MICROMEANS}

\author{
Semantic \\ Grammatical \\ Lexical \\ Textual
}

The model sketched in Figure 1 owes much to the approaches discussed in the previous section: to House (and Wilss 1983) the concept of the close interrelation between macro- and micro-dimensions of language; to Halliday (1978) and Crystal and Davy (and subsequently House and Mason) the notion of the primacy of the "social context" in which a text is located; to Zydatiss the emphasis on text pragmatics; to Newmark the high-lighting of the text's/writer's intention and the scale of emotional "tone." There are, however, additions to all the preceding approaches. Macrodimensions are perceived as those dimensions which can characterize the text as a whole; hence in addition to the macrodimensions of situation (social context) and pragmatics (communicative purpose) a third, semiotic dimension is distinguished since, semiotically, a text can figure as a whole (e.g. Herbert's poem "Easter Wings" which visually/graphically symbolizes the "wings" 
of the title). To the micromeans (which function as "instruments for the establishing of the text-pragmatic level" [Wilss 1983: 147]) has been added textual means (following House [1981]) and also semantic means. The latter is distinguished from House's lexical means on the grounds that it deals with information selection which may vary between source and target text according to the perceived "needs" of the readership, in contrast to lexical means which focus on the type of vocabulary (formal/informal, technical/nontechnical, foreign/native) and types of collocational patterning. Further, while grammatical, lexical and textual means are relevant to establishing cohesion, information selection is a means of achieving coherence (cf. Blum-Kulka, 1986: 24).

Another characteristic of the model is the building-in of contrastive language-pair based considerations. Domain / form-specific features — originally investigated in Crystal and Davy's stylistic analysis method - can be established by research and language-pairs can be contrasted in this respect provided the situational dimensions are kept constant (see for example Emery 1989). Discourse is regulated in different ways in different languages and while one would expect the communicative purposes of the text to be held constant in translation (i.e. the illocutionary force) the manner in which such illocutionary acts are performed "that is their local structure, their style and internal organisation... will vary from culture to culture and context to context" (Van den Broeck 1986: 39). Hence Grice's maxims are not invariably universals but can be language-specific: for example Arabic written discourse has been characterised as repetitive (Williams 1984, Holes 1984) and from an "English" point of view would sometimes seem to "violate" the counsel of "brevity" under the maxim of manner. Similar observations might be established by research about the application of the other maxims of Quality, Quantity, and Relevance in Arabic spoken and written discourse. Such information when used "contrastively" is vitally important for the translator. Text structure refers to the ways in which cohesion is built up and the strategies by which coherence is established. In regard to Arabic/English a number of studies of differential cohesive and rhetorical patterning have been carried out (q.v. Holes 1984, Johnstone 1987) and attention has also been focussed on contrastive theme-dynamics (Williams 1984, Aziz 1988) and conflicting text-strategies (Saadeddin 1987). Text tone refers to the degree of emotiveness of the language of the text; the choice of lexis and the type of lexical patterning can subtly contribute to the realisation of the writer's overall intention. Saj' (or rhymed prose) is used in modern Arabic argumentative and sales discourse to strike an aesthetic chord in the mind of the reader and thereby facilitate the goal of conviction. A sarcastic or bitterly ironic tone can be built up by the use of exaggerated epithets and images; a factual or neutral flavour by the selection of objective (non-personal) structures. In general text tone is preserved in translation but there are cases (e.g. English understatement) where "connotative compensation" will be required. Finally, under the third macrodimension there are differing relationships "between signs and what they stand for" (Basnett-McGuire 1980: 27) in different cultures; in the Arabic version of a Tourist Guide to Tangier the visitor is encouraged to gaze over the sea to sahil alandalus (the shore of Andalusia) while the English-speaking visitor is told of "the splendid view... over the Straits of Gibraltar, with the Rock clearly visible." The phenomenon of "intertextuality" may pose formidable problems in translation: it is mainly because of this that Dagut (1987) doubts whether culture-bound metaphors can actually be "translated." In general one would expect the functions of the text, variation between text-types and purposes of the text producer to be kept constant in moving from source to target text. The main aim here is elicitation of these three aspects, given that the intentions of the text/text producer may not be transparent or at least evident at first glance. Nevertheless, it is possible that the text-producer and the translator may have 
differing aims if the purpose for which the translation is being effected is taken into account (see Lindquist 1988).

The subcategories under Situational Dimensions have been adapted from House (1981): dimensions of language user (geographical origin, social class, time) have been collapsed into Variety of Language. In practice "geographical dialect" is the most evident variable in the type of texts handled in the advanced translation-teaching context, but "social class" and "time" features may also occur. Medium ("channel of communication") is as in House's model and her categories of Social Role Relationship and Social Attitude have been brought together under formality. Like other analytical models the one described above is not designed to be applied serially but rather constitutes an attempt to formalise the initial phase of the translation process in an ideal (i.e. maximally "faceted") way. In the final section of this paper, I consider (briefly) the application of the model and how the analytical phase of the translation process relates to the translation-teaching operation as a whole.

\section{TEXT ANALYSIS AND TRANSLATION TEACHING}

Analysis is merely the first phase of the mental operation of translation, the other phases being "synthesis" in the two-phase model or "transfer" and "restructuring" in Nida's three-phase model (Wilss 1983: 147). The text analysis model outlined above is not a rigid procedure to be applied mechanistically on every text, but an artifical didactic construct - a kind of reference grid or checklist to be used flexibly and selectively. Although it has been asserted earlier that determination of social/situational context is procedurally prior to that of other macrodimensions for the purpose of text classification and analysis, there is nothing in the model which precludes entering into the analysis through the other dimensions. Variety is an essential ingredient in translation teaching (as in all teaching) and, furthermore, texts may vary in the extent to which they can be characterised along the different dimensions: literary texts often need to be interpreted semiotically and vocative texts pragmatically, while informative texts being contentoriented would primarily need to be analysed "situationally."

A comparable flexibility is required in balancing the analytic and synthetic phases of the translation process. Newmark (1988: 21) identifies two approaches to translating: (1) partial translation/reading of a text, (2) close reading of the whole text. In practice the translator generally combines the two approaches, translating here and there while continually reading and analysing. The translator's mind constantly shifts between the twin poles of decoding/restructuring in a kind of continuous cybernetic tension and the translation-teaching class should attempt to reflect this dynamic process - albeit palely. The translation class should never be allowed to settle into a routine but this does not preclude controls in grading and sequencing of materials e.g. a progression from standardised to non-standardised texts, simple to complex, non-technical to technical (cf. Newmark's scale of "generality"). Similarly, variety is necessary in translation pedagogy: the time-honoured method is for the teacher and students to "work out" the target text "together" (i.e. with the students volunteering various renderings which are then "evaluated" by the teacher/expert). A fruitful variation of the method is a "parallel text" approach in which, in addition to the analysis of the source text, the target text is evaluated and the translator's strategies are examined in the light of both language-pair independent and language-pair bound generalizations on translation. The former could be exemplified by Newmark's principle that "expressive" texts are translated semantically (in fact research into Arabic/English literary translations has shown that this is by no means always so (see Shamaa 1979); the latter by contrasting conventions of text 
structure of the type mentioned by Thiel (1985). Also, as an alternative to teacherselection of texts, students may be asked to choose for themselves a text of a particular form from a particular domain, perform an analysis, produce a target text and comment on the strategies they have employed in arriving at their translation. As well as heightening the students' awareness of the complementarity of the analytic and synthetic aspects of the translation process, this procedure enables them to learn about the dimensions of linguistic usage in a practical rather than a theoretical way (learning by doing) and develops the faculty of self-criticism and self-evaluation which is indispensable for the practising professional translator.

\section{NOTES}

1. The notion of "form" is analagous to Crystal and Davy's category of Modality insofar as it refers to an "overall, conventionalised spoken or written format... which may be given a descriptive label" (op. cit.: 74). The dimension of modality is dispensed with by House (1977: 48) on the grounds that "Modality will always remain equivalent for source and translation texts" but this is not necessarily the case in translation between culturally distant languages where "forms" may be non-correspondent for cultural/linguistic reasons (e.g. hadith in English; certain advertisement styles in Arabic).

2. To emphasize the analytical/decoding phase is not necessarily to detract from the restructuring phase of the translation process: as Zydatiss (op. cit.: 221) states, "Just as important as the adequate decoding of the source text would seem to be the translator's awareness of the likely target language norms..."

BIBLIOGRAPHY

AZIZ, Y. (1988): "Theme-rheme Organization and Paragraph Structure in Standard Arabic," WORD, 39-2, pp. 117-128.

BASNETT-McGUIRE, S. (1980): Translation Studies, London, Methuen.

BEAUGRANDE, R. and W. DRESSLER (1981): Introduction to Text Linguistics, London, Longman.

BLUM-KULKA, S. (1986): Shifts of Cohesion and Coherence in Translation, J. House / Blum-Kulka (Eds).

BROWN, G. and G. YULE (1983): Discourse Analysis, Cambridge, CUP.

CATFORD, J. (1965): A Linguistic Theory of Translation, Oxford, OUP.

CRYSTAL, D. and D. DAVY (1969): Investigating English Style, London, Longmans.

DAGUT, M. (1987): "More About the Translatability of Metaphor," Babel, 33-2, pp. 77-83.

EMERY, P.G. (1989): "Legal Arabic Texts: Implications for Translation," Babel, 35-1, pp. 1-11.

HALLIDAY, Mak (1978): Language as a Social Semiotic, Arnold.

HATIM, B. (1984): "A Text-Typological Approach to Syllabus Design in Translator Training," The Incorporated Linguist, 23-3, pp. 146-149.

HOLES, C. (1984): Textual Approximation in the Teaching of Academic Writing to Arab Students: A Contrastive Approach, Swales and Mustapha.

HOUSE, J. (1981): A Model for Translation Quality Assessment, Tübingen, Narr.

HOUSE, J. and S. BLUM-KULKA (Eds.) (1986): Interlingual and Intercultural Communication, Tuibingen, Narr.

JOHNSTONE, B. (1987): "Parataxis in Arabic: Modification as a Model for Persuasion," Studies in Language, $11-1$, pp. 85-97.

LINDQUIST, H. (1988): "Translation Always Has a Purpose", G.M. Anderman and M.A. Rogers (Eds), Translation Studies: State of the Art, CTLS, University of Surrey, vol. I.

MASON, I. (1982): "The Role of Translation Theory in the Translation Class," Quinquereme, 5-1, pp. 18-33.

NEWMARK, P. (1988): A Textbook of Translation, Prentice-Hall.

NIDA, E.A. and C. TABER (1969): The Theory and Practice of Translation, Leiden.

SAADEDDIN, M.A. (1987): "Target-World Experiential Matching: The Case for Arabic/English Translating," Quinquereme, 10-2, pp. 137-164.

SCHMIDT, S.J. (1978): "Some Problems of Communicative Text Theories", W. Dressler (Ed.), Current Trends in Textlinguistics, Berlin, de Gruyter.

SHAMAA, N. (1979): A Linguistic Analysis of Some Problems of Arabic to English Translation, Ph.D. Thesis, University of Oxford.

SWALES, J. and H. MUSTAPHA (Eds) (1984): ESP in the Arab World, Aston University Press.

TANGIER (n.d.): Office national marocain du tourisme (English / Arabic).

THIEL, G. (1985): Parallel Text Production: An Alternative in Pragmatically Oriented Foreign Language Courses, C. Titford and A.E. Hieke (Eds): Translation in Foreign Language Teaching and Testing.

VAN DEN BROECK, R. (1986): "Contrastive Discourse Analysis as a Tool for the Interpretation of Shifts in Translated Texts", House and Blum-Kulka. 
WERLICH, U. (1976): A Text Grammar of English, Heidelberg, Quelle \& Meyer.

WIDDOWSON, H. (1979): Explorations in Applied Linguistics, Oxford, Oxford University Press.

WILLIAMS, M. (1984): “A Problem of Cohesion", Swales and Mustapha.

WILSS, W. (1983): "Translation Strategy, Translation Method and Translation Technique: Towards a Clarification

of Three Translational Concepts," in Revue de phonétique appliquée, pp. 66-68, pp. 143-152.

ZYDATISS, W. (1983): “Text Typologies and Translation," The Incorporated Linguist, 22-4, pp. 212-221. 